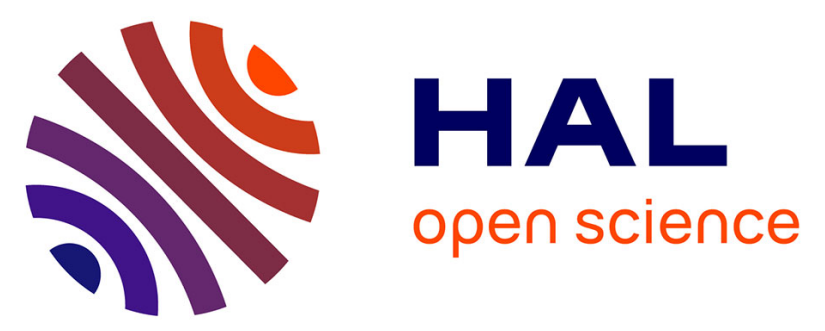

\title{
Poly(3,4-ethylenedioxythiophene):poly(styrene sulfonate)/polyethylene oxide electrodes with improved electrical and electrochemical properties for soft microactuators and microsensors
}

Kätlin Rohtlaid, Giao T. M. Nguyen, Caroline Soyer, Eric Cattan, Frederic Vidal, Cedric Plesse

\section{To cite this version:}

Kätlin Rohtlaid, Giao T. M. Nguyen, Caroline Soyer, Eric Cattan, Frederic Vidal, et al.. Poly(3,4ethylenedioxythiophene):poly(styrene sulfonate)/polyethylene oxide electrodes with improved electrical and electrochemical properties for soft microactuators and microsensors. Advanced Electronic Materials, 2019, 5 (4), pp.1800948. 10.1002/aelm.201800948 . hal-03142273

\author{
HAL Id: hal-03142273 \\ https://hal.science/hal-03142273
}

Submitted on 14 Sep 2021

HAL is a multi-disciplinary open access archive for the deposit and dissemination of scientific research documents, whether they are published or not. The documents may come from teaching and research institutions in France or abroad, or from public or private research centers.
L'archive ouverte pluridisciplinaire HAL, est destinée au dépôt et à la diffusion de documents scientifiques de niveau recherche, publiés ou non, émanant des établissements d'enseignement et de recherche français ou étrangers, des laboratoires publics ou privés.

\section{(ㄷ)(1) $\$$}

Distributed under a Creative Commons Attribution - NonCommerciall 4.0 International 


\title{
Poly(3,4-ethylenedioxythiophene):Poly(styrene sulfonate)/ Polyethylene Oxide Electrodes with Improved Electrical and Electrochemical Properties for Soft Microactuators and Microsensors
}

\author{
Kätlin Rohtlaid, Giao T. M. Nguyen, Caroline Soyer, Eric Cattan, Frédéric Vidal, \\ and Cédric Plesse*
}

The development of microsystems is a rapidly evolving field which enables a wide range of applications for electroactive materials. Microelectromechanical actuators based on electronically conducting polymers are elaborated with an up-scalable process. Commercial poly(3,4-ethylenedioxythiophene):poly(styrene sulfonate) (PEDOT:PSS) is chosen as an easily processable electrode to ensure the reproducibility for further technological production and practical applications. First, the improvement of electrical, electrochemical, and mechanical properties of the PEDOT:PSS electrodes is described by incorporating reactive additives, that is, glycol-based monomers (mPEG) as polyethylene oxide (PEO) network precursors. Moreover, the custom fit layer-by-layer (LbL) process to integrate these PEDOT:PSS/PEO composite electrodes into trilayer microactuators is presented. The incorporation of PEO within PEDOT:PSS improves significantly the electromechanical performances of the resulting microactuators with significant strain $(0.82 \%)$ and high output forces $(472 \mu \mathrm{N})$ compared to similar PEDOT based or pristine PEDOT:PSS microactuators. This work provides also the first demonstration that mechanical strain sensing behavior, extensively studied at macroscale, still occurs at microscale for these trilayer systems. Additionally, to this proof of concept, it highlights that output signal is significantly enhanced by downsizing the devices compared to similar macroscale samples. These results open promising perspectives in the development of numerous applications for soft and scalable microactuators and microsensors.

\section{Introduction}

Soft actuators, also called artificial muscles, are polymer-based materials or devices that are able to generate work when electrically stimulated, similar to biological

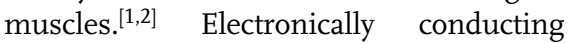
polymers (ECPs), such as polypyrrole (PPy), polyaniline, and poly(3,4-ethylenedioxythiophene) (PEDOT) have been intensively investigated for this purpose not only due to their low operating voltages and large strains, but also, because they are soft, lightweight, easily processed and manufactured. ${ }^{[3-6]}$ These polymers undergo reversible dimensional changes in response to electrical stimuli through redox process in the presence of the electrolyte. ${ }^{[1]}$ Additionally, they can also operate in reverse mode as strain sensors, converting mechanical stimulation into electrical response. ${ }^{\text {[7] }}$

The concept and possible designs of micro electromechanical actuators based on ECPs were demonstrated by Baughman in 1991. ${ }^{[3]}$ Smela et al. demonstrated the fabrication of millimeter scale polymer fingers, made of PPy/gold bilayer strips in 1993. ${ }^{[8]}$ Over the next years, Jager et al. reported the fabrication of different microstructures as microfluidic system, cell clinic, and microactuators for different biomedical applications, able to operate in different environments (salt solutions, blood plasma, urine, and cell culture medium) $\cdot{ }^{[9-13]}$ Even though these bilayer microactuators have been operated in special environments, they were still restricted to operation in liquid electrolyte, limiting their use in different applications. The operation in open air can be obtained using trilayer configuration of the actuator, where two electroactive electrodes are separated by solid polymer electrolyte (SPE), playing the role of ion reservoir. The air-operating ECP-based microactuator was demonstrated first by Alici et al. in 2009. ${ }^{[14]}$ The fabrication method was adapted from the macroscopic process and downscaling of the $155 \mu \mathrm{m}$-thick device was performed using laser ablation. Another way of realizing air-operating ECP-based 
microactuators was introduced by Khaldi et al. in 2011. ${ }^{[15]}$ The microactuator was fabricated with interpenetrating polymer network (IPN) configuration, where two PEDOT electrodes were interpenetrated through chemical oxidative polymerization on both sides of a $10 \mu \mathrm{m}$-thick SPE membrane. Owing to the low thickness, the collective patterning of the actuators was achievable by photolithography and reactive ion etching (RIE). Most of the reported air-working microactuator fabrication methods required manual handling at some step of the process which makes it difficult and time-consuming to fabricate and downscale these devices. To minimize any manual handling, a layerby-layer (LbL) synthesis was recently developed by Maziz et al. by fabricating and operating trilayer microactuators directly on a substrate. ${ }^{[16]}$ This process is based on sequential layer stacking on top of previous layers. The PEDOT layers were obtained from successive vapor phase polymerization (VPP) on the substrate and on the in situ polymerized SPE layer. This work also demonstrated the possibility of integrating bottom gold electrical contact with top-down approach on a flexible substrate. More recently, the electroactivity of the PEDOT electrodes was greatly improved by incorporating glycol-based monomers (mPEG) during the VPP. ${ }^{[17]}$ These PEDOT electrodes were then used to fabricate microactuators with LbL synthesis and resulted in the improvement of the microactuator's performances with maximum strain of $0.5 \%$ and maximum output force of $11 \mu \mathrm{N}$. However, this process requires washing step in order to remove the oxidant and the residuals of the EDOT monomer after VPP synthesized electrodes, is poorly compatible with microsystem process and susceptible to promote lift-off from the substrate, arising in problems during the fabrication process.

Poly(3,4-ethylenedioxythiophene):poly(styrene sulfonate) (PEDOT:PSS) is a commercially available conducting polymer dispersion. This aqueous dispersion has the advantage of easy processing through various methods, such as drop casting, spray coating, spin coating, and ink-printing techniques. ${ }^{\left[{ }^{5}, 18-23\right]}$ Although PEDOT:PSS is known as a promising candidate for many applications due to its remarkable properties, it also has shortcomings when it comes to electrical and electrochemical properties. To overcome these issues, many research groups around the world have reported the enhancement of the electronic conductivity of PEDOT:PSS by thermal, light, acid, organic solvent, ionic liquid, and surfactant treatments. ${ }^{[24-31]}$ Such improvements have made PEDOT:PSS a front-line player in organic electronic devices, such as solar cells and light-emitting diodes, ${ }^{[32-36]}$ especially when stretchability is involved. However, most of the studies on PEDOT:PSS are focused on the improvement of electrical conductivity but not on their electrochemical properties. The improvement in electrochemical properties has been sparsely reported for Li-Ion batteries by the inclusion of lithium salts or by increasing the temperature of the electrochemical cell ${ }^{[37,38]}$ or for energy storage devices, such as supercapacitors, by the incorporation of ethylene glycol and Triton-X surfactants. ${ }^{[39,40]}$ Concerning electroactive soft actuators, the use of PEDOT:PSS as an electrode material has tremendously increased in recent years due to its flexibility and high thermal and chemical stability. Different research groups have reported the fabrication of PEDOT:PSS electrodes with different additives, such as ionic liquid, poly(ethylene oxide) (PEO), single-walled carbon nanotubes, and multi-walled carbon nanotubes to improve the performances of the resulting actuators. ${ }^{[41-45]}$ Only a minor research has been reported for PEDOT:PSS microactuators. Taccola et al. demonstrated the fabrication of PEDOT:PSS/ SU-8 bilayer fingers but the limiting factor of this work was the operation in liquid electrolyte. ${ }^{[46]}$ Põldsalu et al. reported the fabrication of ink-jet printed PEDOT:PSS microactuators where bending actuation was demonstrated in air. ${ }^{[47]}$ Unfortunately, the process appears insufficient for microactuator fabrication, requiring flipping the substrate to obtain the PEDOT:PSS electrodes on both faces of the ionic membrane.

In this work, we propose a simple and effective fabrication method for PEDOT:PSS microactuators with LbL process. The polyethylene glycol methacrylate derivatives (mPEG) are incorporated into the PEDOT:PSS dispersion and its effect on electrical and electrochemical properties of the electrodes will be discussed. The Young's modulus, electrochemical behavior, bending actuation, and blocking force of the microactuators will be presented. Moreover, the mechanical strain sensing ability, widely described and studied for these types of materials at macroscale, has never been described on microscale devices. In this work, we demonstrate for the first time that the sensing properties of conducting polymer actuators are still occurring at microscale and present higher output voltage signal compared to similar type macroactuators.

\section{Results and Discussion}

The general procedure for the LbL fabrication and patterning of microactuators based on PEDOT:PSS/PEO composite electrodes is presented in Figure 1. Typically, it consists of successive stacking of electrodes and ionic conducting membrane followed by a final polymerization step to obtain a trilayer configuration device without any manual handling.

\subsection{PEDOT:PSS/PEO Composite Electrodes}

High electronic conductivity $(\sigma)$ is necessary for obtaining fast and homogeneous bending along the length of the actuator. It is also found that the bending amplitude is ruled by the strain of electrically conducting polymer (ECP) $(\varepsilon)$ which is linked to the strain to charge ratio $\alpha\left(\mathrm{m}^{3} \mathrm{C}^{-1}\right)$ and the volumetric charge density $\rho\left(\mathrm{C} \mathrm{m}^{-3}\right)$ of the conducting polymer layers by an empirical relationship: $\varepsilon=\alpha \rho .^{[48]}$ Therefore, the higher is the charge density, the higher will be the actuation strain due the number of inserted/expelled ions during the redox process. As a consequence, these parameters have to be maximized. Based on these principles, the study of electrical and electrochemical properties of the electrodes was carried out in the absence and in the presence of PEO network precursors (mPEG). In the latter, a radical polymerization initiator is introduced in order to perform mPEG polymerization leading to a PEO network within the PEDOT:PSS electrodes.

Since this work is dealing with the fabrication of microactuators, relatively thick PEDOT:PSS/PEO layers of about ten microns thick were targeted. The PEDOT:PSS electrodes with PEO network precursors (mPEG) were fabricated using casting 


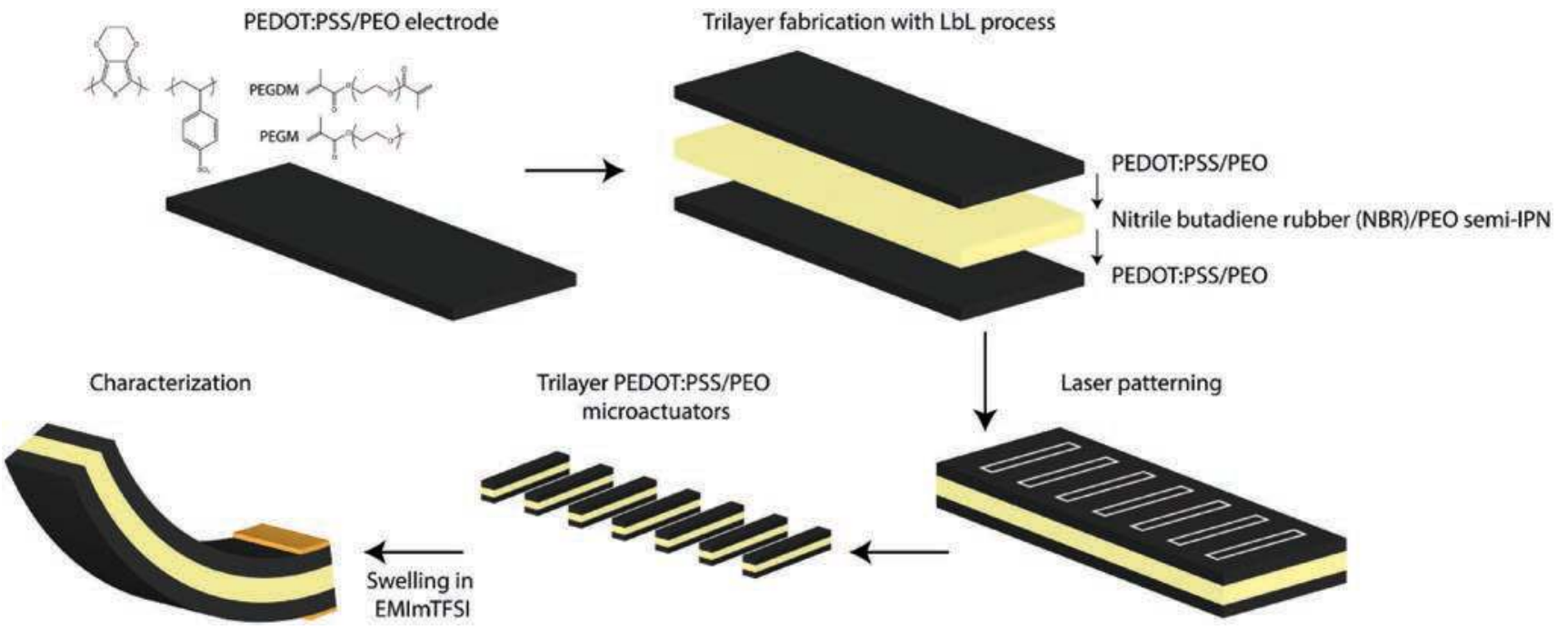

Figure 1. PEDOT:PSS/PEO microactuator fabrication with $L b L$ process.

method. ${ }^{[22,23]}$ The PEO network precursors (expressed vs final mass of the electrode), containing $50 \mathrm{wt} \%$ poly(ethylene glycol) dimethacrylate (PEGDM) and $50 \mathrm{wt} \%$ poly(ethylene glycol) methyl ether methacrylate (PEGM) were added to the commercial Clevios PH1000 aqueous dispersion with water soluble radical initiator ammonium persulfate (APS, $3 \mathrm{wt} \%$ vs $\mathrm{mPEG}$ ). The resulting solution was casted $\left(0.08 \mathrm{ml} \mathrm{cm}^{-2}\right)$ into previously prepared microscope slide molds, which were then placed on a heating plate at $50{ }^{\circ} \mathrm{C}$ to evaporate the water and to form freestanding PEDOT:PSS electrodes. A final heat treatment was carried out under argon during $3 \mathrm{~h} 45 \mathrm{~min}$ at $50^{\circ} \mathrm{C}$ and $1 \mathrm{~h}$ at $80^{\circ} \mathrm{C}$ to promote the free radical polymerization of $\mathrm{MPEG}$ within the PEDOT:PSS electrodes. These obtained PEDOT:PSS/PEO composite electrodes were immersed into ionic liquid (EMImTFSI) prior to the characterizations.

\subsubsection{Effect of PEO Content}

The effect on electrical and electrochemical properties of the PEDOT:PSS electrodes was studied as a function of the PEO content (0-60 wt\%). The electrodes were fabricated as described

a)

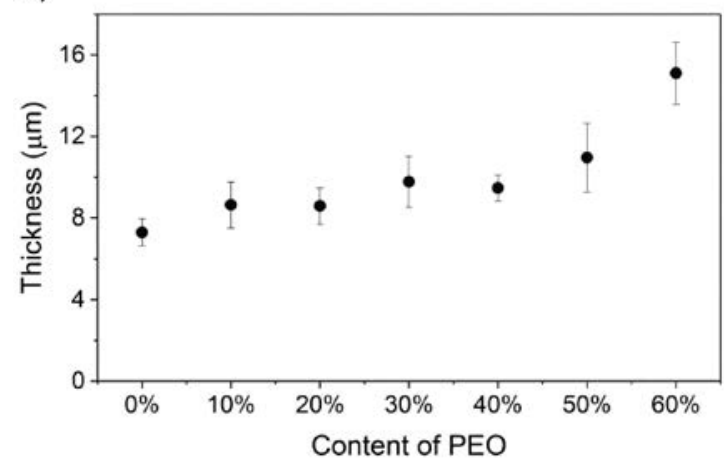

in the previous section. Thickness, electronic conductivity and electroactivity of each electrode are characterized when swollen by electrolyte (EMImTFSI).

The thickness of each PEDOT:PSS/PEO layer was obtained by multiple scans ( 3 to 5 ) across the width of the casted layers $(2 \mathrm{~cm})$ and at different locations along the length $(7 \mathrm{~cm})$ (Figure S1, Supporting Information). Data and error bars demonstrate that, except the plate edges, casting method provides satisfying thickness homogeneity of the layers. Figure 2a presents the increase in thickness when the content of PEO is increased. The thickness is increasing from $7.3 \mu \mathrm{m}$ (0\% PEO) to $15.1 \mu \mathrm{m}(60 \%$ PEO) due to the presence of higher solid content in the casting solution. Moreover, the presence of PEO precursors enhances the electronic conductivity of the PEDOT:PSS electrodes (Figure $2 \mathrm{~b}$ ). It must be mentioned that conductivity measurements have been made over distances close to the dimensions of our transducers $(7 \mathrm{~mm})$ and must be considered as an average value over these distances. The electronic conductivity of the pristine PEDOT:PSS electrode was $1 \mathrm{~S} \mathrm{~cm}^{-1}$ and reached the maximum value of $163 \mathrm{~S} \mathrm{~cm}^{-1}$ at a concentration of $40 \%$ PEO in the electrodes. Even though the electrode with $50 \%$ PEO in the electrodes presented slightly higher electronic

b)

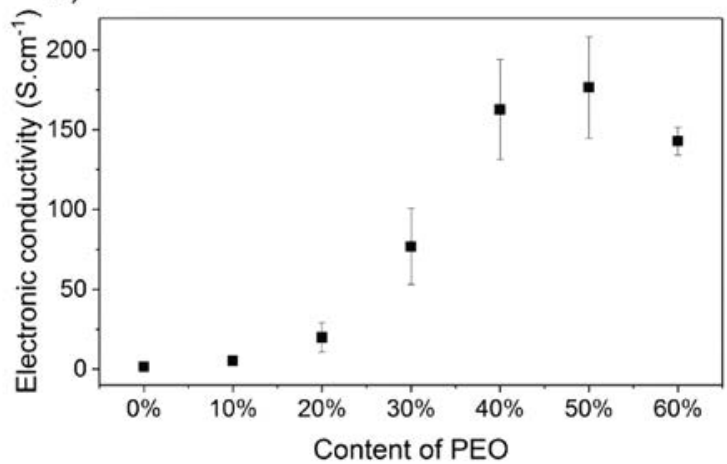

Figure 2. a) Thickness and b) electronic conductivity of PEDOT:PSS electrodes in swollen state (EMImTFSI) as a function of the PEO content. 


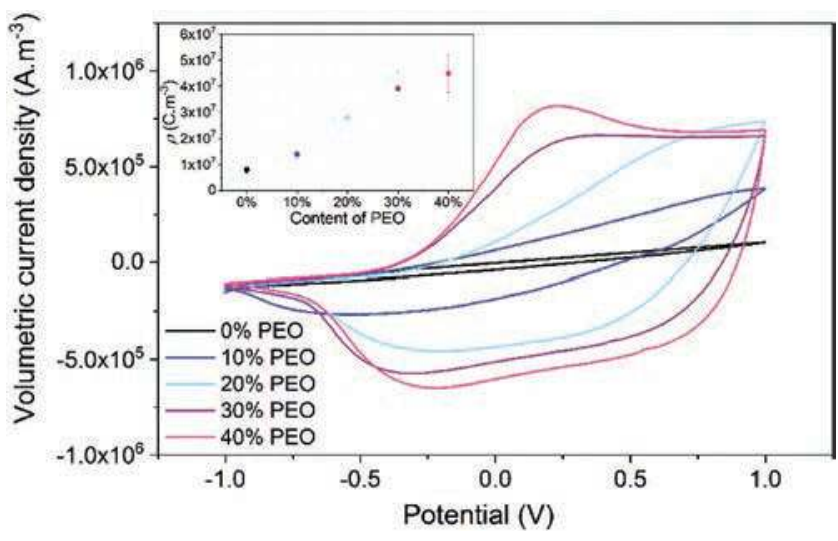

Figure 3. Cyclic voltammetry with an inset of volumetric charge density of PEDOT:PSS electrodes as a function of PEO content at a scan rate of $20 \mathrm{mV} \mathrm{s}^{-1}$ and a voltage window of $\pm 1.0 \mathrm{~V}$ in EMImTFSI.

conductivity, then some phase separation occurred, leading to partly wet and nonhomogeneous surface. As a consequence, the electrode composition with $40 \%$ PEO in the electrodes was considered as the maximum content to fabricate reproducible electrodes. Although insulating PEO phase is diluting the conductive part of the PEDOT:PSS/PEO electrode, the electronic conductivity is increased by two orders of magnitude. Similar improvement was observed for PEDOT:PSS-high molecular weight PEO composite thin film demonstrating that the beneficial effect of PEO derivative is observed not only in thin films, but also for thicker films. ${ }^{[33]}$

As another important parameter for efficient bending type actuator, the influence of the PEO content on electrochemical properties of the PEDOT:PSS/PEO composite electrodes was studied. Figure 3 depicts the cyclic voltammograms of the electrodes with an inset of the volumetric charge density $\rho$. The cyclic voltammetry demonstrates a progressive increase in current when higher content of PEO is incorporated to the electrodes. The PEDOT:PSS electrode with 40\% PEO presents high current density with clearly defined oxidation and reduction peaks. The presence of PEO as an additive allows the redox process to take place more efficiently within the PEDOT:PSS electrodes and then, allows the ion exchanges necessary for the volume variation of the layer. PEO is known to be a good material for ion transport and is probably helping ions to access the PEDOT domains within the composite electrodes. The same behavior was observed in the case of VPP PEDOT electrodes, where incorporation of PEO improved both, the electrical and electrochemical properties. ${ }^{[17]}$ The volumetric charge density $\rho$ allows to evaluate quantitatively the electroactivity of the PEDOT:PSS electrodes. The inset in Figure 3 confirms the increase in electrochemical properties when PEO is incorporated as an additive into the PEDOT:PSS solution: $\rho$ increases from $8.0 \times 10^{6}$ to $4.5 \times 10^{7} \mathrm{C} \mathrm{m}^{-3}$ when $40 \%$ PEO is incorporated into the electrodes, demonstrating a sixfold increase compared to the pristine PEDOT:PSS electrode.

In conclusion, it was found that adding PEO as an additive into the PEDOT:PSS casting solution significantly increases both, the electrical and electrochemical properties of the electrodes up to a maximum threshold of $40 \%$ PEO in the electrodes. As a result, the PEDOT:PSS electrode containing 40\% PEO was considered as the composite electrode for following investigation and is assigned as PEDOT:PSS/PEO electrode.

\subsubsection{PEDOT:PSS Electrodes with $40 \%$ PEO}

The morphology of the PEDOT:PSS electrodes was studied using Atomic Force Microscopy (AFM) in order to understand the effect of the additives in the electrodes. The pristine PEDOT:PSS electrode and the PEDOT:PSS/PEO electrode were analyzed as fabricated. The surface of the PEDOT:PSS film is modified from granular to fibrous structure by the addition of PEO network (Figure 4a,b). These morphological changes are also known to improve the conductivity of the PEDOT:PSS electrodes. ${ }^{[49-51]}$ The addition of PEO can induce phase separation between the hydrophobic PEDOT and the hydrophilic PSS, creating a better connected network between PEDOT fibers and allowing an improved electronic charge transport along the electrode. Moreover, the resulting fibrous and interconnected morphology is also most likely the reason for improved electrochemical properties of the PEDOT:PSS electrodes. Additionally to the presence of PEO, which should improve significantly the ionic conductivity within the PEDOT:PSS layer, ${ }^{[52]}$ such morphology is possibly providing higher accessibility of PEDOT domains to ionic species.

In order to evaluate the dimensional stability of the PEDOT:PSS-based electrodes in the presence of PEO, the obtained electrodes were immersed into water. The effect of each
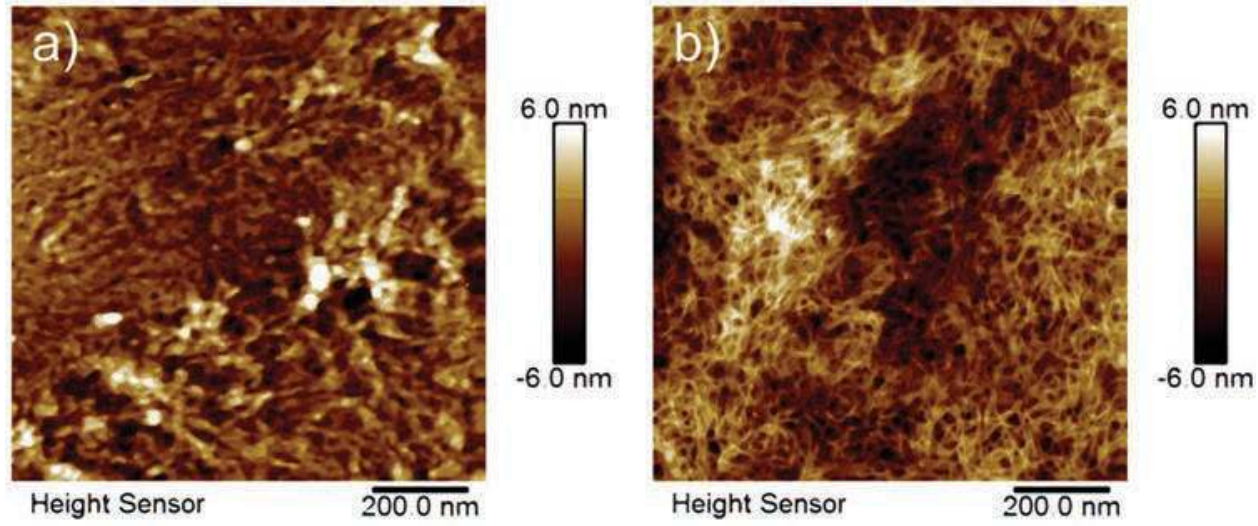

Figure 4. AFM images of PEDOT:PSS films: a) pristine PEDOT:PSS; b) PEDOT:PSS/PEO. 


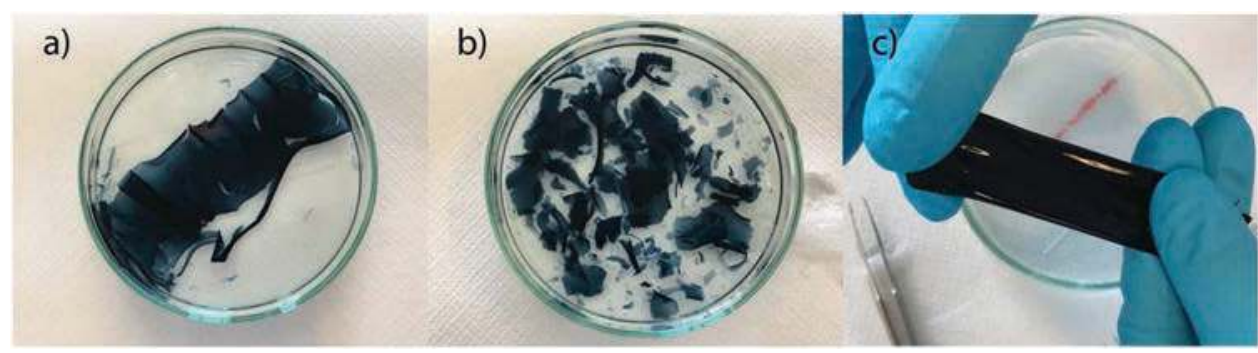

Figure 5. PEDOT:PSS films: a) pristine PEDOT:PSS just after immersion into water; b) pristine PEDOT:PSS after 10 min water immersion; c) PEDOT:PSS/ $\mathrm{PEO}$ electrode after $10 \mathrm{~min}$ water immersion.

precursor or initiator (mPEG or APS) on PEDOT:PSS electrodes was studied separately and the results are presented in Figure S4, Supporting Information. Figure 5a,b shows that the pristine PEDOT:PSS film broke down into small pieces after $10 \mathrm{~min}$. On the other hand, the PEDOT:PSS/PEO electrode was stable and remained as a strong film even while removing from the water. It was still possible to handle and to stretch the electrode without breaking it into pieces (Figure $5 \mathrm{c}$ ). These results demonstrate the beneficial effect of additives to fabricate PEDOT:PSS electrodes with improved electrical but also electrochemical and mechanical properties which is an asset for the elaboration of robust and efficient electromechanical microdevices.

\subsection{PEDOT:PSS/PEO Based Microactuators}

The synthesis of the trilayer actuators was performed according to LbL synthesis, described elsewhere. ${ }^{[16]}$ The process was tailored to be compatible with PEDOT:PSS as an electrode material.
Microactuators with pristine PEDOT:PSS and PEDOT:PSS/PEO composite electrodes were fabricated in order to evaluate the effect of PEO on the performances of the resulting PEDOT:PSS microactuators.

\subsection{Fabrication of PEDOT:PSS/PEO Microactuators}

The fabrication process of the trilayer microactuators (Figure 6a) is described in detail in the experimental section, but shortly, it combines casting of the PEDOT:PSS-based layers and spin-coating and polymerization of the semi-interpenetrating polymer network (semi-IPN) precursors. The semi-IPN layer is composed of PEO network and nitrile butadiene rubber (NBR). These steps allow precise control in thickness of every layer because the volume of the casted solution and the rotation speed of spin-coater can be easily adjusted. In the last step, the microactuators are obtained via laser ablation technique and are swollen in EMImTFSI before further characterizations.

a)

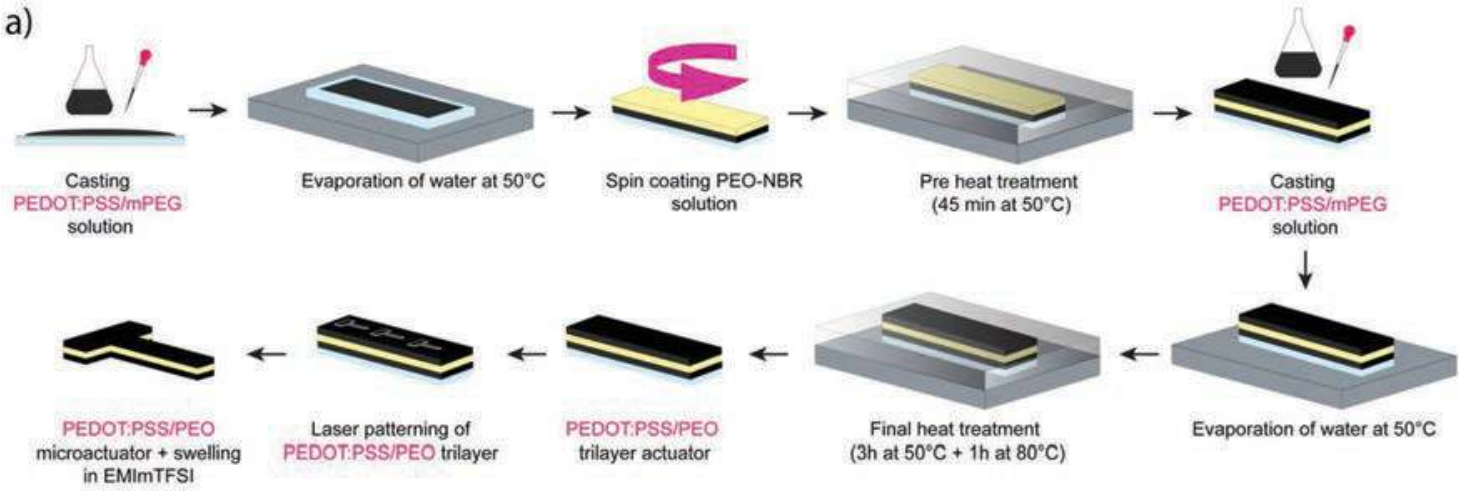

b)

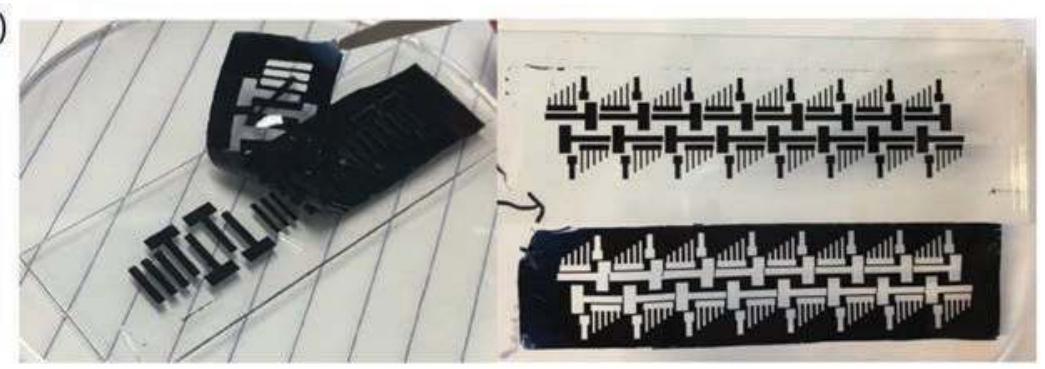

Figure 6. a) Microactuator fabrication process based on LbL synthesis (PEDOT:PSS with $0 \%$ and $40 \%$ PEO); b) photographs of the laser patterned PEDOT:PSS-based microactuators. 
Table 1. The Young's modulus values of PEDOT:PSS microactuators and the calculated Young's modulus values of corresponding PEDOT:PSS electrodes.

\begin{tabular}{lccc}
\hline & $E_{\text {trilayer }}[\mathrm{GPa}]$ & $t_{\text {electrode }}[\mu \mathrm{m}]$ & $E_{\text {electrode }}[\mathrm{GPa}]$ \\
\hline PEDOT:PSS & 2.8 & 7.3 & 5.8 \\
PEDOT:PSS/PEO & 0.9 & 9.2 & 1.6 \\
\hline
\end{tabular}

Resulting laser patterned PEDOT:PSS-based microactuators are illustrated in Figure $6 \mathrm{~b}$. The length and the width of the obtained microbeams were 6.8 and $1.2 \mathrm{~mm}$, respectively. The thicknesses were 29.7 and $34.6 \mu \mathrm{m}$ for the pristine PEDOT:PSS and PEDOT:PSS/PEO microactuators, respectively.

\subsubsection{Mechanical Properties}

Stiffness of the beams was measured during mechanical bending experiments. The stiffness is calculated from the relationship between the applied displacement and resulting forces, allowing to determine the Young's modulus of the microbeams. The PEDOT:PSS microactuator has relatively high Young's modulus (2.8 GPa) compared to the PEDOT:PSS/PEO microactuator $(0.9 \mathrm{GPa})$ (Table 1). This trend has also been reported in the literature, suggesting that incorporating additives dilutes the casting solution and helps to form more fibrous PEDOT:PSS with less dense structure and therefore lower Young's modulus. ${ }^{[4]}$ The equation below is then used to derive Young's modulus of the electrodes separately:

$E_{\text {electrode }}=\frac{\left(E_{\text {trilayer }} t_{\text {trilayer }}\right)-\left(E_{\mathrm{PEO}-\mathrm{NBR}} t_{\mathrm{PEO}-\mathrm{NBR}}\right)}{2 t_{\text {electrode }}}$

where $E_{x}$ and $t_{x}$ are the Young's modulus (MPa) and the thickness $(\mu \mathrm{m})$ of the corresponding layers. The thicknesses of the PEDOT:PSS layers are obtained from the electrode study. The Young's modulus of the PEO-NBR membrane is approximately $1 \mathrm{MPa}$ and the thickness $15 \mu \mathrm{m}$ (determined after swelling in EMImTFSI). ${ }^{[53]}$ The derived results for the electrodes are brought in Table 1. The pristine PEDOT:PSS electrode presents really high Young's modulus $(5.8 \mathrm{GPa})$, which is also higher compared to the values reported in the literature for PEDOT:PSS films $(\approx 2.5 \mathrm{GPa}) .{ }^{[54,55]}$ The derived modulus of the PEDOT:PSS/PEO electrode is $1.6 \mathrm{GPa}$. Overall, these results demonstrate softening of the microactuators and electrodes when PEO is incorporated to the PEDOT:PSS layers.

\subsubsection{Electrochemical Properties}

The electrochemical properties of the PEDOT:PSS microactuators were determined using cyclic voltammetry $( \pm 1.0 \mathrm{~V}, \pm$ $2.0 \mathrm{~V}, 20 \mathrm{mV} \mathrm{s}^{-1}$ ). Figure 7 illustrates the cyclic voltammetry of the microactuators with an inset of volumetric charge density $\rho$. Both of the microactuators present double-layer capacitor-like behavior at a potential window of $\pm 1.0 \mathrm{~V}$. The curve of the PEDOT:PSS microactuator remains similar also at wider potential window $( \pm 2.0 \mathrm{~V})$, indicating that the resistive behavior of pristine PEDOT:PSS electrodes prevents efficient redox process to take place. The PEDOT:PSS/PEO microactuator shows a redox process occurring at higher potential range $( \pm 2.0 \mathrm{~V})$. These results are consistent with the work of Okuzaki et al. where it was found that IL/PU/PEDOT:PSS actuators present capacitor behavior at lower voltages and a redox behavior at voltages higher than $1.5 \mathrm{~V} \cdot{ }^{[41]}$ The inset of volumetric charge densities confirms the increasing trend of electroactivity at higher potentials and even further when PEO is incorporated to the PEDOT:PSS electrodes. The resulting values of $\rho$ for PEDOT:PSS microactuator are $9.0 \times 10^{6}$ and $2.6 \times 10^{7} \mathrm{C} \mathrm{m}^{-3}$ at voltage windows of \pm 1.0 and $\pm 2.0 \mathrm{~V}$, respectively. The corresponding values for PEDOT:PSS/PEO microactuator are $2.7 \times 10^{7}$ and $7.7 \times 10^{7} \mathrm{C} \mathrm{m}^{-3}$ at voltage windows of \pm 1.0 and $\pm 2.0 \mathrm{~V}$. The volumetric charge density of the PEDOT:PSS/PEO microactuator is three times higher at both voltage windows compared to the pristine PEDOT:PSS microactuator. Higher electrochemical performances of the PEDOT:PSS/PEO microactuators can be related, as for electrode study, to the fibrous structure of the PEDOT:PSS electrode and the presence of PEO (AFM image, Figure 4), promoting good ion transport in the PEDOT phase and improving therefore the charge transport in the electrodes.

\subsubsection{Actuation Characterization}

The actuation characterizations of the microactuators were performed as a function of square wave potential between 0.4 and $2.2 \mathrm{~V}$ at a frequency of $0.1 \mathrm{~Hz}$. It can be seen from Figure 8, that applied potential has an effect on the strain difference of both microactuators. For both samples, the strain difference is increasing with the voltage and seems to reach a plateau beyond $1.6 \mathrm{~V}$, indicating that the maximum deformation of the device is reached. Regardless of the applied potential, the strain difference is notably higher in the presence of PEO. The pristine PEDOT:PSS microactuator reached the maximum value of $0.19 \%$ at the highest applied potential of $2.2 \mathrm{~V}$. This value is relatively low and can be explained by both, low electronic conductivity and low volumetric charge density of the pristine

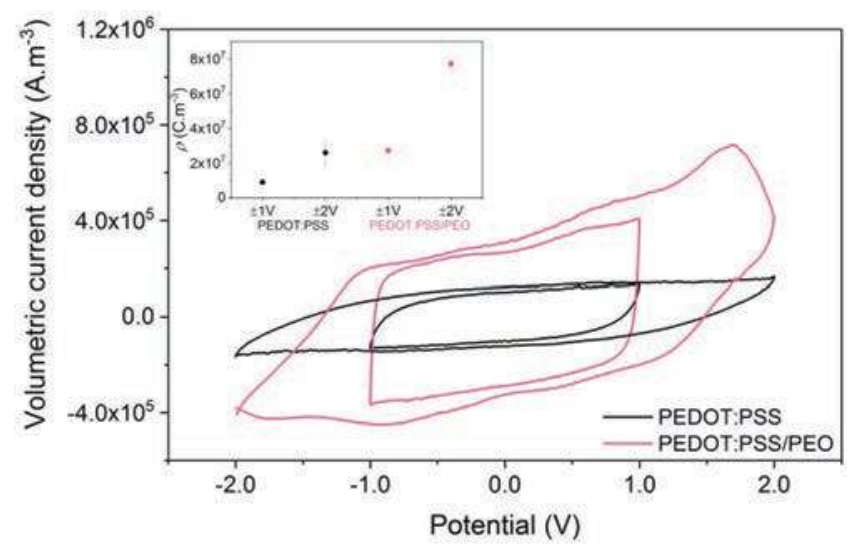

Figure 7. Cyclic voltammetry with an inset of volumetric charge density of PEDOT:PSS and PEDOT:PSS/PEO microactuators at a scan rate of $20 \mathrm{mV} \mathrm{s}^{-1}$ and a voltage windows of \pm 1.0 and $\pm 2.0 \mathrm{~V}$. 


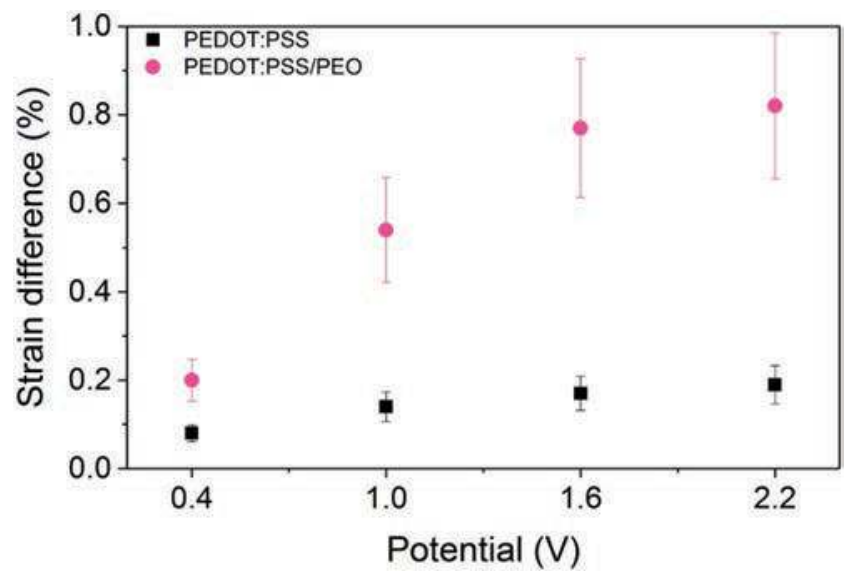

Figure 8. Strain difference (\%) as a function of applied potential at a frequency of $0.1 \mathrm{~Hz}$ of the PEDOT:PSS and PEDOT:PSS/PEO microactuators.

PEDOT:PSS electrodes. The PEDOT:PSS/PEO microactuator reached the maximum value of $0.82 \%$ also at $2.2 \mathrm{~V}$. It confirms that the incorporation of PEO is also beneficial for the strain performances, most likely related to higher volumetric charge density and therefore a better charge transport in the composite electrodes, but also to the lower Young's modulus which facilitates their bending. Finally, it should be mentioned here that the bending direction during oxidation of the working electrode correspond to a volume contraction. In other words, during oxidation the $\mathrm{EMI}^{+}$cations are expelled from the oxidized PEDOT electrodes, which is consistent with the cation mobile mechanism previously reported for PEDOT macroactuators using EMITFSI as electrolyte. ${ }^{[56]}$

\subsubsection{Blocking Force Characterization}

The blocking force measurements were carried out as a function of applied potential at $0.1 \mathrm{~Hz}$ (Figure 9). At low potential $(0.4 \mathrm{~V})$, the generated forces for pristine PEDOT:PSS and PEDOT:PSS/PEO microactuators are 120 and $208 \mu \mathrm{N}$, respectively. As observed previously for strain, the

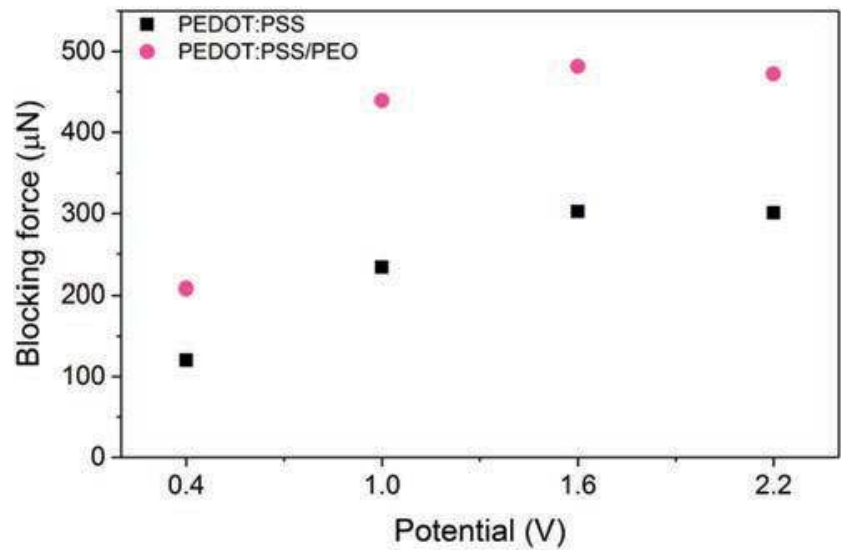

Figure 9. Blocking force (at $3.0 \mathrm{~mm}$ from clamping) as a function of applied potential of the PEDOT:PSS and PEDOT:PSS/PEO microactuators. The length and the width of the microbeams are 6.8 and $1.2 \mathrm{~mm}$, respectively. output force is increasing with the increase of the potential for both microactuators until $1.6 \mathrm{~V}$ before reaching a plateau. The maximum values at $1.6 \mathrm{~V}$ for the PEDOT:PSS and PEDOT:PSS/PEO microactuators are 301 and $472 \mu \mathrm{N}$, respectively. This indicates that the output force is only improved by a factor 1.5 between pristine PEDOT:PSS and PEDOT:PSS/PEO microactuators, while a fourfold increase was measured for strain values. This result can appear surprising taken into account the enhanced electrical and electrochemical properties, but can be explained by an electromechanical model proposed by Alici et al. showing that the output force is directly proportional to the Young's modulus of the electrodes. ${ }^{[57]}$ The values of Young's modulus (Table 1) demonstrated the electrodes softening when PEO was incorporated, which consequently may decrease the generated forces of the final microbeam. Supposedly it can be a trade-off between electronic conductivity, electroactivity, and Young's modulus where the first two improve the overall performances of the PEDOT:PSS/PEO microactuator but softening of the electrodes limit the output force. Nevertheless, output forces in the range of hundreds of $\mu \mathrm{N}$ can be obtained which is considerably higher compared to previously described LbL VPP PEDOT microactuators, where the maximum force was $11 \mu \mathrm{N}$. ${ }^{[17]}$ This large improvement can be of course attributed to the geometry factor (two times thicker and two times shorter measurement distance in the present study) but also to the difference in Young's modulus between PEDOT obtained through VPP and PEDOT:PSS/ PEO electrodes, around $20 \mathrm{MPa}^{[58]}$ and $1.6 \mathrm{GPa}$ respectively.

\subsubsection{Sensor Characterization}

Depending on external stimuli (electrical or mechanical stimulation), ECP-based devices are known to act both, as actuators or as strain sensors. The mechanism behind the voltage generation in sensor mode is not fully defined yet, but there are several proposed mechanisms with experimental characterizations to understand better this voltage generation. Wu et al. introduced the "Deformation Induced Ion Flux" model to explain the estimation of the magnitude and the polarity of the sensor response. ${ }^{[7]}$ Shoa et al. proposed a model, indicating that external application of stress alters the internal stress of ions, helping to insert or remove charge and as a consequence, to change the voltage. ${ }^{[59]}$ More recently, the "piezoionic effect" has been introduced to explain the voltage generation through inhomogeneous ionic distribution, based on the Donnan potential. ${ }^{[60]}$ All these ECP sensors were only described at macroscale, with variation of open circuit voltages (OCV) usually in the range of $\mathrm{mV}$ or lower. However, there is no prediction based on theoretical model and no experimental demonstration to know if such behavior still occurs for microsized samples and which voltage amplitude can be generated.

In this work, mechanical bending is applied to the microactuators and OCV is recorded. The upper layer of the device was connected to the working electrode and during upward bending displacement the top electrode was then compressed. The length and the width of the characterized microbeams were 6.8 and $1.2 \mathrm{~mm}$, respectively. 
a)
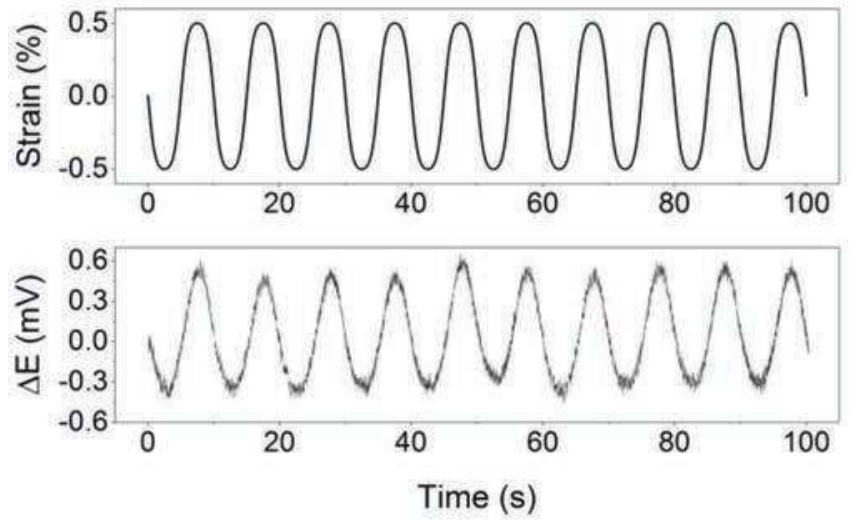

b)

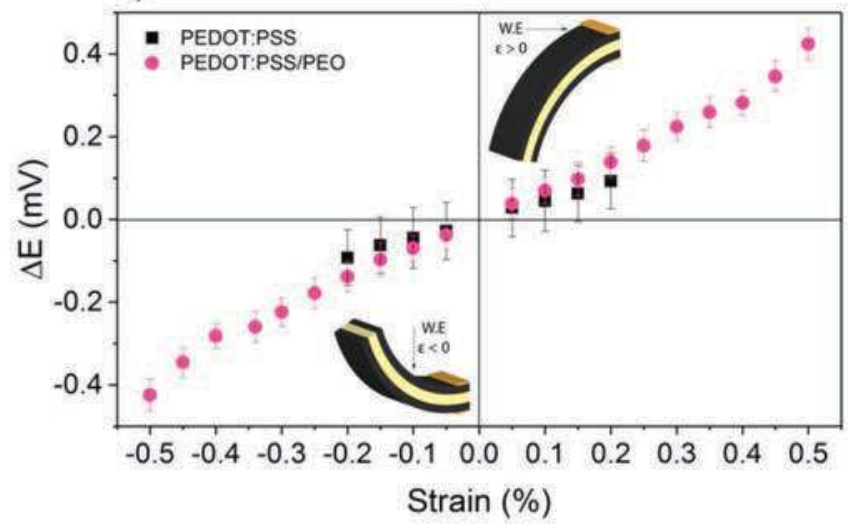

Figure 10. a) Open circuit voltage $(\Delta E)$ response of PEDOT:PSS/PEO microsensor to the sinusoidal mechanical stimulation at a strain of $0.5 \%$; b) Open circuit voltage $(\Delta E)$ response to the sinusoidal mechanical stimulation as a function of applied strain at a frequency of $0.1 \mathrm{~Hz}$ of the PEDOT:PSS and PEDOT:PSS/PEO microsensors.

Figure 10a presents the sinusoidal mechanical stimulation (strain amplitude $\pm 0.5 \%$ ) applied to the PEDOT:PSS/ PEO microbeam as a function of time with the corresponding OCV variation. It demonstrates a good correlation between strain and electrical response indicating that the detection of mechanical stimulation at microscale is possible. The signal is corresponding to an in-phase response, that is, a positive strain of the working electrode corresponding to an increase of the OCV. The sign of the voltage variation is consistent with previously reported results on PEDOT macro-samples in the case of ionic liquids where it was demonstrated that the more mobile ionic species are the cations. ${ }^{[56]}$ During compression/expansion of the working electrode, the mechanically induced ion flux is promoting dominant motion of cations from or towards the electrodes, respectively. In other words, we demonstrate here that the same ion motion mechanism is taking place in macro-samples and also in the microsized ones.

Figure 10b presents the amplitude of OCV variation measured during mechanical stimulation of the microbeams for applied strain ranging between -0.5 and $0.5 \%$ at a frequency of $0.1 \mathrm{~Hz}$. It can be observed that OCV is modified during mechanical stimulation and the variation increases linearly with the amplitude of the mechanical stimulation with a sensitivity close to $0.74 \mathrm{mV} \%^{-1}$. These results demonstrate that conducting polymer-based microbeams are effectively behaving as strain microsensors, able to detect but also to quantify a mechanical deformation. The pristine PEDOT:PSS microsensor reaches a maximum value of $0.09 \mathrm{mV}$ at a strain of $0.2 \%$. It must be mentioned here that applying higher strain tends to break the samples, probably because of stiffer electrodes and consequently more brittle devices. The PEDOT:PSS/PEO microbeam presents almost identical response but can be stimulated up to $0.5 \%$. For this amplitude, the OCV variation is equal to $0.42 \mathrm{mV}$. This result at a strain of $0.5 \%$ is approximately ten times higher compared to the values reported in previous work on thick trilayer macrodevices. ${ }^{[56]}$ Therefore, downsizing such microdevices not only allows to still detect mechanical stimulation, but it also provides higher sensitivity. Considering that ion flux is driven by stress gradient across the thickness of the device, a decrease of the device's thickness for the same applied strain tends to proportionally increase the stress gradient and then can be the main factor of the observed sensitivity enhancement.

Figure 11 interprets the applied step displacement of $-0.5 \%$ strain, that is, bending leading to the contraction of the working electrode, and the OCV variation $(\triangle \mathrm{E})$ for PEDOT:PSS/PEO microsensor. The responses during $30 \mathrm{~s}$, 1 and 5 min follow the same trend and a negative output voltage signal of approximately $-0.4 \mathrm{mV}$ was produced during the compression of the working electrode. However, the electrical signal evolution over time is different compared to other reported ECP-based trilayer sensors. Indeed, in the reported cases, an electrical signal relaxation is observed when maintaining constant strain, ultimately going back to initial value. ${ }^{[56]}$ This typical relaxation phenomenon can be explained by the piezoionic effect introduced by Sarwar et al. ${ }^{[60]}$ When applying mechanical stimulation, the mechanically induced cation flux from the compressed electrode is creating disequilibrium of ions and generating the OCV variation. However, since both, cations and anions are mobile in classical electrolytes or ionic liquids, the less mobile anions are also diffusing over time, to progressively compensate this concentration difference. As a consequence, the OCV variation is progressively going back to $0 \mathrm{mV}$. This behavior can be considered as a drawback since it allows detecting dynamic stimulation but prevents any direct relationship between the position of the device and the $\mathrm{OCV}$ value. Interestingly, in the case of the PEDOT:PSS/PEO electrodes, the high concentration of nonmobile PSS $^{-}$anions within the electrodes probably tends to limit the relaxation compared to classical ECP electrodes. This situation seems to be similar to the behavior of IPMCs where only one type of mobile ions exist (cations), since anions are attached to the perfluorosulfonic membranes. In this case, no relaxation is also observed. ${ }^{[61]}$ This result is especially interesting since it allows sensing not only dynamical mechanical perturbation but also relating the OCV value directly to the steady position of the microsensor, facilitating their further use in practical microsystems. 

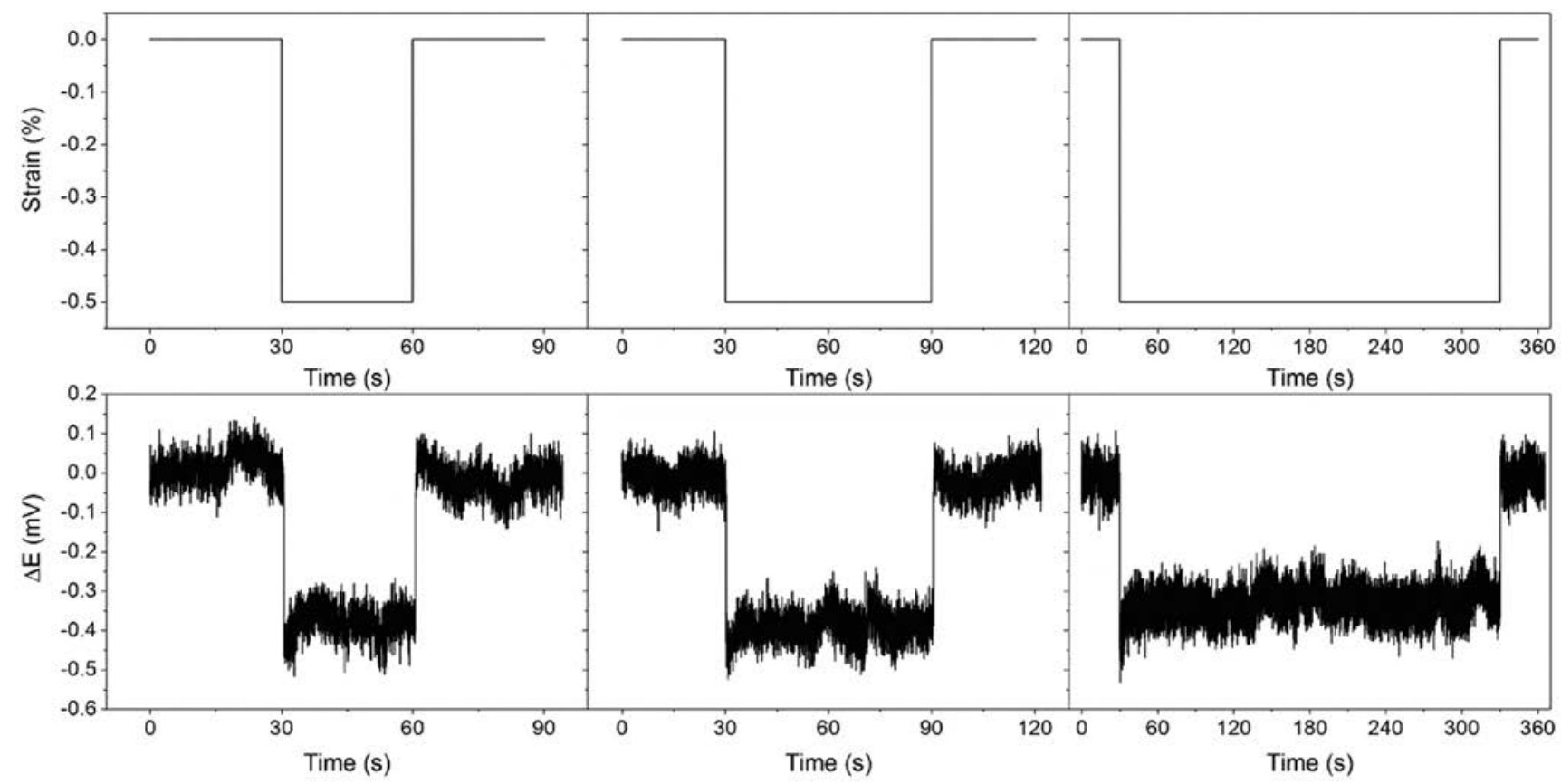

Figure 11. PEDOT:PSS/PEO microsensor output voltage in response to the square wave mechanical stimulation with an applied strain of $0.5 \%$ during $30 \mathrm{~s}, 1 \mathrm{~min}$, and $5 \mathrm{~min}$.

\section{Conclusions}

The solution casted PEDOT:PSS electrodes were fabricated counting PEO as a beneficial additive to improve the electrical and electrochemical properties of the electrodes. The incorporation of the PEO into the PEDOT:PSS electrodes resulted in high electronic conductivity $\left(163 \mathrm{~S} \mathrm{~cm}^{-1}\right)$ and high volumetric charge density $\left(4.5 \times 10^{7} \mathrm{C} \mathrm{m}^{-3}\right)$. The PEDOT:PSS-based actuators were fabricated with tailored LbL synthesis and micropatterned using laser ablation technique. Two types of microactuators with different electrode compositions (PEDOT:PSS and PEDOT:PSS/ PEO) were fabricated in order to evaluate the effect of PEO on microactuators performances. The PEDOT:PSS/PEO microactuators resulted in improvement of all the studied parameters compared to the pristine PEDOT:PSS microactuators and presented large strains $(0.82 \%)$ and high output forces $(472 \mu \mathrm{N})$. We also demonstrated for the first time that such microdevices are able to present sensing properties and that their sensitivity is even higher to that of their thick macroscopic counterparts. These results are opening promising perspectives in the fabrication of complex actuating/sensing microsystems where these easily processed electroactive materials could be combined together and interfaced with integrated electrical contacts.

\section{Experimental Section}

Materials: Poly(ethylene glycol) methyl ether methacrylate (PEGM, $M_{n}=500 \mathrm{~g} \mathrm{~mol}^{-1}$ ), poly(ethylene glycol) dimethacrylate (PEGDM, $\mathrm{M}_{n}=750 \mathrm{~g} \mathrm{~mol}^{-1}$ ), ammonium persulfate (APS, 98\%), and cyclohexanone (>99.8\%) were obtained from Sigma-Aldrich and used as received. PEDOT:PSS aqueous solution (Clevios $\mathrm{PH} 1000$, solid content $1.0-1.3$ wt\%) was purchased from Heraeus Precious Metals $\mathrm{CmbH} \&$ Co. Nitrile-butadiene rubber (NBR), initiator dicyclohexyl peroxydicarbonate
(DCPD), and 1-ethyl-3-methylimidazolium bis(trifluoromethanesulfonyl) imide (EMImTFSI 99.9\%) were used as supplied from LANXESS, Groupe Arnaud, and Solvionic, respectively.

Fabrication of Electrode Layers: PEDOT:PSS electrodes were fabricated using casting method. ${ }^{[22,23]}$ The network of PEO precursors (mPEG) is composed of $50 \mathrm{wt} \%$ of PEGM and $50 \mathrm{wt} \%$ of PEGDM as the monomer and the crosslinker, respectively, which are added $(0 \%-60 \%$, vs final electrode, that is, $40-100 \%$ PEDOT:PSS, considering solid content of $1.15 \mathrm{wt} \%)$ to the commercial Clevios PH1000 PEDOT:PSS aqueous solution. Additionally, APS as a radical initiator for PEO precursors, was added ( $3 \mathrm{wt} \%$ vs $\mathrm{mPEG)}$ to the solution. The solution was stirred until dissolution and degassed. Microscope slides as the substrates were prepared for casting by covering the edges with a scotch, allowing for the solution to solidify in the "mold". The obtained PEDOT:PSS solution was casted $\left(0.08 \mathrm{ml} \mathrm{cm}^{-2}\right)$ into the molds and the substrates were then placed on a heating plate at $50^{\circ} \mathrm{C}$ to let the water evaporate and to form free-standing PEDOT:PSS/mPEG electrodes. The heat treatment was carried out under argon, for $3 \mathrm{~h} 45 \mathrm{~min}$ at $50{ }^{\circ} \mathrm{C}$ and $1 \mathrm{~h}$ at $80^{\circ} \mathrm{C}$. The obtained PEDOT:PSS/PEO composite electrodes were swollen in ionic liquid (EMImTFSI) prior to the characterization.

Fabrication of Trilayer Microactuators: The synthesis of the trilayer actuators was performed according to LbL synthesis as described elsewhere. ${ }^{[16]}$ This process was tailored to be compatible with PEDOT:PSS as the new electrode material (Figure 6) which does not require washing step. The PEDOT:PSS casting solutions were obtained by mixing Clevios $\mathrm{PH} 1000$ commercial solution, PEO precursors ( $0 \mathrm{wt} \%$ and $40 \mathrm{wt} \%$ ), and APS ( $3 \mathrm{wt} \%$ vs PEO), as described in the previous paragraph for electrode fabrication. The solution was casted $\left(0.08 \mathrm{ml} \mathrm{cm}{ }^{-2}\right)$ into previously prepared molds and the substrates were placed on a heating plate at $50^{\circ} \mathrm{C}$, to evaporate the water and to form self-standing electrodes.

The SPE, as an ion storage membrane and an insulator between two electrodes, is based on the semi-interpenetrating polymer network (semi-IPN) structure. The semi-IPN layer (PEO-NBR, 50-50 wt\%) is polymerized in situ and is composed of a PEO network and a linear NBR, where the former provides the membrane with the ionic conductivity (when introduced to the electrolyte) and the latter with the mechanical properties. First, the NBR solution was prepared by dissolving NBR 
(20 wt\%) in cyclohexanone and stirred until complete dissolution. The PEO precursors, consisting of PECDM ( 25 wt\% vs PEO network) and PEGM ( $75 \mathrm{wt} \%$ vs PEO network) were added to the NBR solution and stirred for $30 \mathrm{~min}$. The radical initiator DCPD (3 wt\% vs PEO network) was then introduced to the solution and the final solution was stirred until complete homogenization and degassed. During the next step, the reactive mixture was spin coated (the spin coating speed, acceleration, and duration were $1500 \mathrm{rpm}, 1000 \mathrm{rpm} \mathrm{s}^{-1}$ and $30 \mathrm{~s}$, respectively) onto the first PEDOT:PSS electrode layer and pre-polymerized in a sealed chamber under argon during $45 \mathrm{~min}$ at $50^{\circ} \mathrm{C}$ to initiate the formation of PEO network.

The second PEDOT:PSS electrode was fabricated on top of the PEDOT:PSS/semi-IPN bilayer in the same way as the first electrode: Solutions were prepared, casted, and solidified at $50^{\circ} \mathrm{C}$ by evaporating the water. Resulting trilayer actuators were then placed to the sealed chamber for the final heat treatment during $3 \mathrm{~h}$ at $50^{\circ} \mathrm{C}$ and $\mathrm{h}$ at $80^{\circ} \mathrm{C}$ under argon. Finally, the fabrication process includes micropatterning of the trilayer structures into microbeams, using laser cutting (Oxford Lasers). The obtained microactuators are then immersed in ionic liquid (EMImTFSI, 72h) to incorporate the ions, necessary for the redox process. The length and the width of the characterized microbeams were 6.8 and $1.2 \mathrm{~mm}$, respectively.

Thickness Measurements: Thickness measurements were performed with profilometers Dektak 150 (Veeco) and Dektak XT (Bruker). Provided values and error bars are obtained from average of multiple measurements ( 3 to 5 ) across the width and at multiple locations along the length (see Figure S1, Supporting Information).

Electrical Measurements: The electronic conductivity of the PEDOT:PSS electrodes was obtained by measuring the sheet resistance of the electrodes with in house built setup. Two gold plates (low resistivity material) were fixed onto the substrate to keep the distance $(d)$ between the gold plates constant. Sheet resistance of the electrodes was measured with digital multimeter Model 2000 (Keithley Instruments). By knowing the distance $(d)$ between the gold plates, the thickness of the electrode $(h)$, the length $\left(I_{x}\right)$ of the electrode that is on the surface of the gold plates and the sheet resistance of the electrode from the multimeter $(R)$, the electronic conductivity $(\sigma)$ was calculated according to the relation between resistivity and conductance from the formula:

$\sigma=\frac{d}{h l_{x} R}$

Electrochemical Measurements: Cyclic voltammetry (CV) of the electrodes was carried out using VMP Multipotentiostat (Biologic SA) in three-electrode configuration. The expanded stainless-steel mesh (Dexmet Corporation) was used as the counter electrode (the surface area twice as the working electrode's area), silver wire as the reference electrode, fabricated electrode as the working electrode and EMImTFSI as the electrolyte. The parameters for $\mathrm{CV}$ were: scan rate: $20 \mathrm{mV} \mathrm{s}^{-1}$; potential range: $\pm 1.0 \mathrm{~V}$; cycles: 5 . CV of the microactuators was performed using VMP Multipotentiostat (Biologic SA) in two-electrode configuration. One PEDOT:PSS electrode of the trilayer configuration was connected to the working electrode and the second PEDOT:PSS electrode to the reference and counter electrodes.

Integration of the current from cyclic voltammetry gives the charge (Q), which is divided by the volume of the electrode, providing volumetric charge density $(\rho)$ :

$\rho=\frac{\int_{0}^{t / 2} i(t) \mathrm{d} t}{\operatorname{lwh}}$

where $i(t)$ is the measured current, $t$ is the duration of one cycle of applied voltage, $l, w, h$ are the length, width, and thickness of the PEDOT:PSS electrodes, respectively.

Atomic Force Microscopy: AFM was used in order to investigate the topography of PEDOT:PSS electrodes. Atomic force microscopy (AFM) images were recorded in tapping mode with Nanoscope $V$ controller, coupled with an icon microscope from Bruker.
Mechanical Characterization: Stiffness of the beams was measured during mechanical bending experiments. The stiffness is calculated from the relationship between the applied displacement and resulting forces, allowing to determine the Young's modulus of the microbeams. The experiments were carried out with the microrobotic system FT-RS1002 (Femtotools) and a microforce sensing probe FT-S1000 (Femtotools). The tip of the sensing probe was in contact with the microactuator at the distance of $3 \mathrm{~mm}$. The displacement was applied and the resulting force was recorded. The Young's modulus was obtained from the relation between the displacement and the force of the microactuators and is calculated following the formula below:

$E=\frac{4 k L^{3}}{w h^{3}}$

where $k$ is the slope of the recorded force and displacement curve, $L$ is the distance between the clamped end of the microactuator and the tip of the force sensor, $w$ and $h$ are the width and thickness of the microactuator, respectively.

The Actuation Experiments: The bending deformation of the microactuators was determined by applying square wave potential $( \pm 0.4$ to $\pm 2.2 \mathrm{~V}$ ) and measuring the passing current through the trilayer microactuator while following the bending deformation/displacement of the microactuator at the frequency of $0.1 \mathrm{~Hz}$. The system consists of the voltage source (NF Electronic instruments 1930) to produce a step voltage and an in-house amplifier, an ampere meter (FW Bell mA-2000) to measure the passing current, a micro camera (Dino-Lite AM7000/ AD7000) to record the bending movement of the microactuator and a laser displacement sensor LKG 32 (Keyence). The strain difference $\varepsilon$ between the two PEDOT:PSS electrodes was calculated according to Sugino, where $D$ is the displacement of the actuator from neutral to actuated state, $h$ is the thickness of the actuator, and $L_{0}$ is the distance between the clamped end of the actuator and the laser beam. ${ }^{[62]}$

$$
\varepsilon=\frac{2 D h}{L_{0}^{2}+D^{2}}
$$

The Blocking Force Experiments: The measurement setup consisted of voltage source (NF Electronic instruments 1930) to produce a step voltage and an in-house amplifier, microrobotic system FT-RS1002 (Femtotools) with a microforce sensing probe FT-S1000 (Femtotools). The microactuator was clamped and connected to the voltage source. The tip of the sensing probe was in contact with the microactuator at the distance of $3 \mathrm{~mm}$. When potential was applied, the bending movement was then counteracted by the tip of the sensing probe and the resulting data was recorded.

Sensor Characterization: Sensor experiments were carried out by applying mechanical stimulation and measuring the responding OCV. The samples were clamped and connected to the VMP Multipotentiostat (Biologic SA). The Dual Mode Lever System (Aurora Scientific, 300C) was used to apply mechanical stimulation and the resulting OCV was recorded with the potentiostat.

\section{Acknowledgements}

The research was supported by the European Union's Horizon 2020 research and innovation program under the Marie Skłodowska-Curie grant agreement No. 641822. This work was partially supported by the French Government through the National Research Agency (ANR) under program PIA EQUIPEX LEAF (ANR-11-EQPX-0025) and by the French RENATECH network. 


\section{Conflict of Interest}

The authors declare no conflict of interest.

\section{Keywords}

layer-by-layer fabrication, microactuators, microsensors, PEDOT:PSS

[1] R. H. Baughman, Synth. Met. 1996, 78, 339.

[2] T. Mirfakhrai, J. D. W. Madden, R. H. Baughman, Mater. Today 2007, $10,30$.

[3] R. H. Baughman, L. W. Shacklette, R. L. Elsenbaumer, E. J. Plichta, C. Becht, Mol. Electron. 1991, 267.

[4] R. H. Baughman, Makromol. Chem., Macromol. Symp. 1991, 51, 193.

[5] L. Groenendaal, F. Jonas, D. Freitag, H. Pielartzik, J. R. Reynolds, Adv. Mater. 2000, 12, 481

[6] J. D. W. Madden, N. A. Vandesteeg, P. A. Anquetil, P. G. A. Madden, A. Takshi, R. Z. Pytel, S. R. Lafontaine, P. A. Wieringa, I. W. Hunter, IEEE J. Oceanic Eng. 2004, 29, 706.

[7] Y. Wu, G. Alici, J. D. W. Madden, G. M. Spinks, G. G. Wallace, Adv. Funct. Mater. 2007, 17, 3216.

[8] E. Smela, O. Inganäs, Q. Pei, I. Lundström, Adv. Mater. 1993, $5,630$.

[9] E. W. H. Jager, E. Smela, O. Inganäs, Sens. Actuators, B. 1999, $56,73$.

[10] P. F. Pettersson, E. W. H. Jager, O. Inganas, presented at 1st Annual Int. IEEE-EMBS Special Topic Conf. on Microtechnologies in Medicine and Biology (Cat. No. 00EX451), Lyon, France, October 2000.

[11] E. W. H. Jager, E. Smela, O. Inganäs, Science 2000, 290, 1540.

[12] E. W. H. Jager, C. Immerstrand, K. H. Peterson, K. E. Magnusson, I. Lundström, O. Inganäs, Biomed. Microdevices 2002, 4, 177.

[13] C. Immerstrand, E. W. H. Jager, K.-E. Magnusson, T. Sundqvist, I. Lundström, O. Inganas, K. H. Peterson, Med. Biol. Eng. Comput. 2003, 41, 357.

[14] G. Alici, M. J. Higgins, Smart Mater. Struct. 2009, 18, 065013.

[15] A. Khaldi, C. Plesse, C. Soyer, E. Cattan, F. Vidal, C. Legrand, D. Teyssié, Appl. Phys. Lett. 2011, 98, 164101.

[16] A. Maziz, C. Plesse, C. Soyer, E. Cattan, F. Vidal, ACS Appl. Mater. Interfaces 2016, 8, 1559.

[17] T. N. Nguyen, K. Rohtlaid, C. Plesse, G. T. M. Nguyen, C. Soyer, S. Grondel, E. Cattan, J. D. W. Madden, F. Vidal, Electrochim. Acta 2018, 265, 670 .

[18] N. Kim, S. Kee, S. H. Lee, B. H. Lee, Y. H. Kahng, Y. R. Jo, B. J. Kim, K. Lee, Adv. Mater. 2014, 26, 2268.

[19] Y. Xia, K. Sun, J. Ouyang, Adv. Mater. 2012, 24, 2436.

[20] M. Cai, Z. Ye, T. Xiao, R. Liu, Y. Chen, R. W. Mayer, R. Biswas, K. M. Ho, R. Shinar, J. Shinar, Adv. Mater. 2012, 24, 4337.

[21] Z. Zhao, G. F. Richardson, Q. Meng, S. Zhu, H. C. Kuan, J. Ma, Nanotechnology 2016, 27, 042001.

[22] H. Yan, T. Jo, H. Okuzaki, Polym. J. 2009, 41, 1028.

[23] H. Okuzaki, H. Suzuki, T. Ito, Synth. Met. 2009, 159, 2233.

[24] J. Huang, P. F. Miller, J. C. De Mello, A. J. De Mello, D. D. C. Bradley, Synth. Met. 2003, 139, 569.

[25] A. Moujoud, S. H. Oh, H. S. Shin, H. J. Kim, Phys. Status Solidi A 2010, 207, 1704.

[26] J. Y. Kim, J. H. Jung, D. E. Lee, J. Joo, Synth. Met. 2002, 126, 311.
[27] C. Badre, L. Marquant, A. M. Alsayed, L. A. Hough, Adv. Funct. Mater. 2012, 22, 2723.

[28] B. Fan, X. Mei, J. Ouyang, Macromolecules 2008, 41, 5971.

[29] Y. Xia, J. Ouyang, Org. Electron. physics, Mater. Appl. 2010, 11, 1129.

[30] Y. Xia, H. Zhang, J. Ouyang, J. Mater. Chem. 2010, 20, 9740.

[31] Y. Xia, J. Ouyang, ACS Appl. Mater. Interfaces 2010, 2, 474.

[32] Y. Wang, C. Zhu, R. Pfattner, H. Yan, L. Jin, S. Chen, F. Molina-Lopez, F. Lissel, J. Liu, N. I. Rabiah, Z. Chen, J. W. Chung, C. Linder, M. F. Toney, B. Murmann, Z. Bao, Sci. Adv. 2017, 3, e1602076.

[33] S. G. R. Bade, X. Shan, P. T. Hoang, J. Li, T. Geske, L. Cai, Q. Pei, C. Wang, Z. Yu, Adv. Mater. 2017, 29, 1607053.

[34] J. H. Lee, Y. R. Jeong, G. Lee, S. W. Jin, Y. H. Lee, S. Y. Hong, H. Park, J. W. Kim, S. S. Lee, J. S. Ha, ACS Appl. Mater. Interfaces 2018, 10, 28027.

[35] P. Li, K. Sun, J. Ouyang, ACS Appl. Mater. Interfaces 2015, 7, 18415.

[36] H. P. Kim, S. J. Lee, A. R. bin Mohd Yusoff, J. Jang, RSC Adv. 2016, 6, 28599.

[37] P. R. Das, L. Komsiyska, O. Osters, G. Wittstock, ECS Trans. 2015, $68,45$.

[38] R. V. Apraksin, A. I. Volkov, S. N. Eliseeva, V. V. Kondratiev, J. Solid State Electrochem. 2017, 21, 3487.

[39] T. Cheng, Y. Z. Zhang, J. D. Zhang, W. Y. Lai, W. Huang, J. Mater. Chem. A 2016, 4, 10493.

[40] T. Cheng, Y. Z. Zhang, J. P. Yi, L. Yang, J. D. Zhang, W. Y. Lai, W. Huang, J. Mater. Chem. A 2016, 4, 13754.

[41] H. Okuzaki, S. Takagi, F. Hishiki, R. Tanigawa, Sens. Actuators, B. 2014, 194, 59.

[42] K. Ikushima, S. John, A. Ono, S. Nagamitsu, Synth. Met. 2010, 160, 1877.

[43] N. Terasawa, K. Asaka, Langmuir 2016, 32, 7210.

[44] N. Terasawa, K. Asaka, Sens. Actuators, B. 2017, 248, 273.

[45] D. Wang, C. Lu, J. Zhao, S. Han, M. Wu, W. Chen, RSC Adv. 2017, 7, 31264.

[46] S. Taccola, F. Greco, B. Mazzolai, V. Mattoli, E. W. H. Jager, J. Micromech. Microeng. 2013, 23, 117004.

[47] I. Põldsalu, K. Rohtlaid, T. Minh, G. Nguyen, C. Plesse, F. Vidal, M. S. Khorram, A. Peikolainen, T. Tamm, R. Kiefer, Sens. Actuators, B 2018, 258, 1072.

[48] J. D. W. Madden, PhD. Thesis, Massachusetts Institute of Technology, 2000.

[49] Y. Xia, J. Ouyang, ACS Appl. Mater. Interfaces 2012, 4, 4131.

[50] B. J. Worfolk, S. C. Andrews, S. Park, J. Reinspach, N. Liu, M. F. Toney, S. C. B. Mannsfeld, Z. Bao, Proc. Natl. Acad. Sci. USA 2015, 112, 14138

[51] P. G. Raj, V. S. Rani, A. Kanwat, J. Jang, Mater. Res. Bull. 2016, 74, 1.

[52] M. B. McDonald, P. T. Hammond, ACS Appl. Mater. Interfaces 2018, 10,15681

[53] N. Festin, A. Maziz, C. Plesse, D. Teyssié, C. Chevrot, F. Vidal, Smart Mater. Struct. 2013, 22, 104005.

[54] U. Lang, J. Dual, Key Eng. Mater. 2007, 345-346, 1189.

[55] D. Tank, H. H. Lee, D. Y. Khang, Macromolecules 2009, 42, 7079.

[56] N. Festin, C. Plesse, P. Pirim, C. Chevrot, F. Vidal, Sens. Actuators, B. 2014, 193, 82.

[57] G. Alici, N. N. Huynh, Sens. Actuators, A. 2006, 132, 616.

[58] N. T. Nguyen, Y. Dobashi, C. Soyer, C. Plesse, G. T. M. Nguyen, F. Vidal, E. Cattan, S. Grondel, J. D. W. Madden, Smart Mater. Struct. 2018, 27.

[59] T. Shoa, J. D. W. Madden, T. Mirfakhrai, G. Alici, G. M. Spinks, G. G. Wallace, Sens. Actuators, A. 2010, 161, 127.

[60] M. S. Sarwar, Y. Dobashi, E. F. S. Glitz, M. Farajollahi, S. Mirabbasi, S. Naficy, G. M. Spinks, J. D. W. Madden, SPIE Smart Struct. Mater. + Nondestruct. Eval. Heal. Monit. 2015, 9430, 943026.

[61] Y. Liu, Y. Hu, J. Zhao, G. Wu, X. Tao, W. Chen, Small 2016, 12, 5074.

[62] T. Sugino, K. Kiyohara, I. Takeuchi, K. Mukai, K. Asaka, Sens. Actuators, B. 2009, 141, 179. 